\title{
Quantitative trait loci (QTL) mapping for growth traits on bovine chromosome 14
}

\author{
Marcelo Miyata ${ }^{1}$, Gustavo Gasparin ${ }^{1}$, Luiz Lehmann Coutinho ${ }^{2}$, Mario Luiz Martinez ${ }^{3}$, \\ Marco Antonio Machado ${ }^{3}$, Marcos Vinicius G. Barbosa da Silva ${ }^{3}$, Ana Lucia Campos ${ }^{3}$, \\ Tad S. Sonstegard ${ }^{4}$, Millor Fernandes do Rosário ${ }^{5}$ and Luciana Correia de Almeida Regitano ${ }^{6}$ \\ ${ }^{1}$ Programa de Pós-Graduação em Genética e Evolução da Universidade Federal de São Carlos, \\ São Carlos, SP, Brazil. \\ ${ }^{2}$ Departamento de Produção Animal, Universidade de São Paulo, Piracicaba, SP, Brazil. \\ ${ }^{3}$ Embrapa Gado de Leite, Juiz de Fora, MG, Brazil. \\ ${ }^{4} U S D A$, ARS Bovine Functional Genomics Laboratory, Beltsville, MD, USA. \\ ${ }^{5}$ Departamento de Genética, Escola Superior de Agricultura Luiz de Queiroz, Piracicaba, SP, Brazil. \\ ${ }^{6}$ Embrapa Pecuária Sudeste, São Carlos, SP, Brazil.
}

\begin{abstract}
Quantitative trait loci (QTL) mapping in livestock allows the identification of genes that determine the genetic variation affecting traits of economic interest. We analyzed the birth weight and weight at 60 days QTL segregating on bovine chromosome BTA14 in a F2 resource population using genotypes produced from seven microsatellite markers. Phenotypes were derived from 346 F2 progeny produced from crossing Bos indicus Gyr x Holstein Bos taurus F1 parents. Interval analysis to detect QTL for birth weight revealed the presence of a QTL $(p<0.05)$ at 1 centimorgan (cM) from the centromere with an additive effect of $1.210 \pm 0.438 \mathrm{~kg}$. Interval analysis for weight at 60 days revealed the presence of a QTL $(p<0.05)$ at $0 \mathrm{cM}$ from the centromere with an additive effect of $2.122 \pm 0.735 \mathrm{~kg}$. The region to which the QTL were assigned is described in the literature as responsible for some growth traits, milk yield, milk composition, fat deposition and has also been related to reproductive traits such as daughter pregnancy rate and ovulation rate. The effects of the QTL described on other traits were not investigated.
\end{abstract}

Key words: TA14, cattle, F2, growth traits, molecular markers, QTL.

Received: March 30, 2006; Accepted: October 24, 2006.

\section{Introduction}

In livestock animals, the main goal of genomic mapping is to identify and characterize genes that affect phenotypic variation in traits of economic relevance. In beef cattle, phenotypic selection for growth has been highly effective due to the ease of measurement and intermediate to high heritabilities (Koots et al., 1994a). There are also moderate to high genetic correlations between growth traits at different ages (Koots et al., 1994b), with selection to increase postnatal growth usually resulting in an increase in birth weight and thus calving difficulty. The increase in postnatal growth maintaining constant birth weight will be facilitated through direct selection based on individual genes or quantitative trait loci (QTL) that influence weight

Send correspondence to Luciana Correia de Almeida Regitano. Embrapa Pecuária Sudeste, Rod. Washington Luis km 234, Caixa Postal 339, 13560-970 São Carlos, SP, Brazil. E-mail: Iuciana@ cppse.embrapa.br. at weaning and at maturity but not during the prenatal period (Kim et al., 2003).

Genetic markers and linkage maps have provided tools to detect QTL in cattle (Stone et al., 1999; Casas et al., 2000; Casas et al., 2001; MacNeil and Gross, 2002) and QTL identification has significantly increased the potential of genetic improvement through implementation of marker assisted selection (MacNeil and Gross, 2002). Most QTL mapping studies have used crosses between Bos taurus and Bos indicus cattle (Stone et al., 1999; Casas et al., 2000) since the probability of finding segregation on QTL is much higher for crossbred populations (Lynch and Walsh, 1998). As part of a project that will scan the bovine genome for several traits we have produced a reference $\mathrm{F} 2$ population from crosses between B. indicus Gyr and B. taurus Holstein cattle (Gasparin et al., 2005).

Beef cattle QTL for growth traits have been reported in numerous studies (Casas et al., 2000). Davis et al. (1998) 
reported significant QTL for birth weight in the centromeric region of bovine chromosome 21 (BTA21) using three half-sib families from $B$. taurus Charolais x Brahman $B$. indicus bulls, in the same position as the most significant QTL for birth weight found by Casas et al. (2003). Machado et al. (2003) using a composite breed developed from the cross of $B$. taurus and B. indicus, detected a QTL for birth weight on the same chromosome. This was probably the same QTL that was segregating in the Gyr-Holstein F2 population described above (Gasparin et al., 2005).

Other authors have identified QTL for growth traits on BTA14, Hetzel et al. (1997) having found a region on this chromosome which is significantly associated with the traits birth weight and weights from six to twelve months. Buchanan et al. (2000) found a significant marker for weaning weight, yearling weight and average daily gain on pasture at $67 \mathrm{cM}$ and another QTL for birth weight and average daily gain in feedlot mapped to the centromeric region of BTA14.

On the basis of previous studies reporting QTL for growth traits, we investigated the presence of QTL for birth weight and weight at 60 days on BTA14 in an experimental F2 population, obtained from crosses between Gyr and Holstein cattle.

\section{Material and Methods}

\section{Animals}

An experimental F2 population was produced by the Brazilian agricultural company Empresa Brasileira de Pesquisa Agropecuária (Embrapa) on the Santa Monica Experimental Station, in the Brazilian state of Rio de Janeiro.

The population was started from 28 Gyr females artificially inseminated with semen from four Holstein bulls, resulting in $150 \mathrm{~F} 1$ offspring (males and females). Five F1 males were chosen to be the parents of the F2 generation and were crossed with $70 \mathrm{~F} 1$ females, preventing kinship between sires and dams, resulting in five families and a total of 346 F2 offspring with birth weight recorded.

\section{DNA extraction}

Samples of blood or semen were collected from each animal, including the F1 and F2 parents, for DNA extraction by the method of Hallerman et al. (1988).

\section{Markers}

Markers were chosen based on map position, number of alleles and heterozygosity, according to information available during February 2004 at the Meat Animal Research Center (MARC) database (http://www.marc.usda. gov). Seven microsatellite markers were selected (CSSM066, ILSTS011, BMC1207, BMS740, BMS1899, BL1036 and BMS2055) that would cover nearly $100 \%$ of chromosome 14, at approximately $20 \mathrm{cM}$ intervals based on the United States Department of Agriculture Meat Animal
Research Center (MARC) reference map (http://www. marc.usda.gov).

\section{Genotyping}

The polymerase chain reactions (PCR) consisted of $50 \mathrm{ng}$ of genomic DNA, $0.20 \mathrm{mM}$ of dNTPs, $1.5 \mathrm{mM}$ $\mathrm{MgCl}_{2}, 0.1 \mu \mathrm{M}$ of each primer and 0.25 units of Taq polymerase (Biotools, Spain) in a total volume of $12.5 \mu \mathrm{L}$. For each locus, the forward primer was labeled with either 6-carboxyfluorescein (6-FAM) or 5'-hexachloro-fluorescein phosphoramidite (Hex) fluorochromes. The amplifications were carried out in a Mastercycler Gradient thermocycler (Eppendorf), with annealing temperatures specific for each primer. The amplification products were analyzed in an ABI Prism 3100 Avant (Applied Biosystems) sequencer with the GeneScan and Genotyper software provided by the manufacturer. Annealing temperatures, fluorescent dyes and the percentage of animals genotyped for each marker in each generation are given in Table 1.

\section{Linkage map}

The linkage map of BTA14 was constructed using the build, prepare and all functions of the CRIMAP software (Green et al., 1990). The chrompic function was used to show the grandparental origins of alleles in each offspring's chromosomes, in relation to the linkage phase choice with the highest likelihood. This function gives the relative probability for this phase choice and for the next most likely alternative, displaying the number and location of recombinations on each chromosome, and provides, for each chromosome interval defined by the loci, a list of the chromosomes having a recombination in that interval. The map was derived from the observed recombination fraction for each marker interval using Kosambi's mapping function (Lynch and Walsh, 1998) to transform recombination into distance.

\section{Statistical analysis}

To estimate the expected heterozygosity $\left(H_{e}\right)$ and the polymorphism information content (PIC) analysis of the allelic frequencies of the markers was carried out with the Cervus v.2.0 software (Marshall et al., 1998).

The QTL statistical analysis was carried out by the linear regression method (Haley et al., 1994) for F2 pedigrees using the QTL Express software (Seaton et al., 2002) at http://qtl.cap.ed.ac.uk. The F-statistic was calculated to test the hypothesis of QTL segregation at $1 \mathrm{cM}$ intervals. For birth weight and weight at 60 days, the model included the fixed effects of sex of the calf and contemporary group (combination of month and year of birth), calving order of the dam as a covariable and additive effect of the QTL. In this study 1,000 permutations were adopted to obtain stable estimates for the value of $\alpha=0.01$ (Churchill and Doerge, 1994). Permutation tests were also applied for the threshold determination (Churchill and Doerge, 1994) and the boot- 
strap method for determination of the confidence interval (CI) for the presence of a possible QTL (Visscher et al., 1996).

The resampling bootstrap method, proposed by Visscher et al. (1996) to determine the confidence interval removes samples (individuals) of the population that contain information about genotype and phenotype, generating a new population with sample replacement in which statistical analysis can be used to identify QTLs. After a preestablished resampling number and QTL analysis of the new populations the $95 \%$ confidence interval (CI) of the QTL is determined by ordering the generated estimates, with $2.5 \%$ of the values representing the upper and lower tails of the distribution. The width of the confidence interval depends on the size of the population and on the QTL effect, although variation between marker spacing does not result in very different confidence intervals (Visscher et al., 1996).

\section{Results}

Analysis of the seven BTA14 microsatellite markers produced a total of 38 alleles, with an average of 5.24 alleles per locus (Table 1). For any genetic marker, a locus with heterozygosity greater than $70 \%$ can be considered as highly polymorphic (Ott, 1999). The number of alleles, heterozygosity and PIC values are show in Table 2. The highest expected heterozygosity was 0.845 for the CSSM066 marker and the lowest was 0.434 for the BMC1207 marker while the average population heterozygosity was 0.716 , indicating that most of the markers used in this work were highly polymorphic (Table 1).

The PIC parameter is generally referred to as a measure of usefulness of a marker locus in linkage (Lynch and Walsh, 1998). In our study, the average PIC value in the population was 0.674 and the highest was 0.824 for the CSSM066 whilst the lowest was 0.385 for the BMC1207 marker (Table 1), these being related to the number and frequency distribution of the alleles in both loci.

The chromosome 14 linkage map obtained from our data has the same marker order as the MARC reference map, but the distance between markers was higher. Differences in sample size and in the number of informative meiosis events may also explain the fact that the $144.3 \mathrm{cM}$ distance between the first and the seventh marker in our map (EMBRAPA) was larger than the $104.5 \mathrm{cM}$ distance shown in the MARC reference map. The number of informative meiosis events for the seven markers is summarized in the last two columns of Table 1.

The Haley et al. (1994) interval analysis for birth weight on BTA14 resulted in a suggestive QTL $(p<0.05)$ at $1 \mathrm{cM}$ from the most centromeric marker (Figure 1). The highest F-statistic value (7.62) was at $1.0 \mathrm{cM}$ between the CSSM066 marker at $0.0 \mathrm{cM}$ and the ILSTS011 marker at $16.9 \mathrm{cM}$. The confidence interval for this QTL was

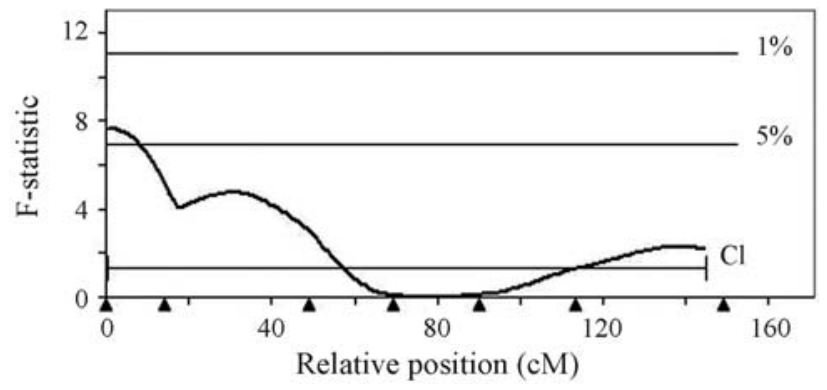

Figure 1 - Chromosome F-statistic distribution for the birth weight quantitative trait locus (QLT) on the chromosome 14 (BTA14). The arrows below the $\mathrm{X}$ axis indicate marker positions on the chromosome as measured from the centromere, in centimorgans (cM): CSSSM066 (0.0 cM), ILSTS011 (16.9 cM), BMC1207 (47.8 cM), BMS740 (67.7 cM), BMS1899 (91.6 cM), BL1036 (116.8 cM) and BMS2055 (144.3 cM). The upper and lower horizontal lines represent threshold levels of $1 \%$ $(\mathrm{F}=11.33)$ and $5 \%(\mathrm{~F}=7.20)$. The QTL is located at $1.0 \mathrm{cM}$ from the centromere $(\mathrm{F}=7.62)$. The scale indicates the $95 \%$ confidence interval $(0.0 \mathrm{cM}$ to $144.0 \mathrm{cM})$.

Table 1 - Microsatellite markers, annealing temperature (T), fluorescent dye (Dye), number and percentage of F1 and F2 offspring genotyped, number of alleles (A), expected heterozygosity $\left(H_{e}\right)$, polymorphism information content (PIC) and informative meiosis comparing the maps produced by the Brazilian agricultural company Empresa Brasileira de Pesquisa Agropecuária (Embrapa) to the reference map produced by the United States Department of Agriculture Meat Animal Research Center (MARC). The markers are placed in order of map position. For each marker we genotyped 32 parent cattle, representing $100 \%$ of parents.

\begin{tabular}{|c|c|c|c|c|c|c|c|c|c|c|c|}
\hline \multirow[b]{2}{*}{ Marker } & \multicolumn{2}{|c|}{ Reaction conditions } & \multicolumn{2}{|c|}{ Genotyped offspring (\%) } & \multicolumn{3}{|c|}{ Allele data } & \multicolumn{2}{|c|}{ Embrapa } & \multicolumn{2}{|c|}{ MARC } \\
\hline & $\mathrm{T}\left({ }^{\circ} \mathrm{C}\right)$ & Dye* & $\mathrm{F} 1$ & $\mathrm{~F} 2$ & A & $H_{e}$ & PIC & $\begin{array}{c}\text { Informative } \\
\text { meiosis }\end{array}$ & $\begin{array}{l}\text { Map posi- } \\
\text { tion }(\mathrm{cM})\end{array}$ & $\begin{array}{l}\text { Informative } \\
\text { meiosis }\end{array}$ & $\begin{array}{l}\text { Map posi- } \\
\text { tion** }(\mathrm{cM})\end{array}$ \\
\hline ILSTS011 & 58 & 6-FAM & $71(96)$ & $361(97)$ & 3 & 0.665 & 0.590 & 641 & 16.9 & 265 & 5.6 \\
\hline BMC1207 & 58 & HEX & $72(98)$ & $337(91)$ & 4 & 0.434 & 0.385 & 324 & 47.8 & 839 & 31.2 \\
\hline BMS1899 & 58 & 6-FAM & $72(98)$ & $364(98)$ & 6 & 0.781 & 0.747 & 623 & 91.6 & 363 & 47.0 \\
\hline BL1036 & 56 & 6-FAM & $72(98)$ & $368(99)$ & 8 & 0.784 & 0.757 & 548 & 116.8 & 249 & 73.7 \\
\hline BMS2055 & 58 & HEX & $72(98)$ & $360(97)$ & 4 & 0.674 & 0.617 & 459 & 144.3 & 422 & 79.1 \\
\hline
\end{tabular}

*HEX $=5$ '-hexachloro-fluorescein phosphoramidite, 6-FAM = 6-carboxyfluorescein.

**Setting CSSM066 as the most centromeric marker. 
$144.0 \mathrm{cM}$, from 0.0 to $144.0 \mathrm{cM}$ in relation to CSSM066, the most centromeric marker. The sex effect was estimated to be $-1.926 \pm 0.570 \mathrm{~kg}$ for the females due to the difference of size between males and females and the additive effect was of $1.210 \pm 0.438 \mathrm{~kg}$, corresponding to $4 \%$ of the trait mean of $29.59 \mathrm{~kg}$. The QTL allele with a positive effect on birth weight was inherited from the Holstein parental breed.

For weight at 60 days the interval analysis on BTA14 resulted in a suggestive QTL $(\mathrm{p}<0.05)$ at $0 \mathrm{cM}$ from the most centromeric marker (Figure 2). The highest F-statistic value (8.34) was at $0.0 \mathrm{cM}$, close to the CSSM066 marker at $0.0 \mathrm{cM}$. The confidence interval for this QTL was $137.5 \mathrm{cM}$, from 0.0 to $137.5 \mathrm{cM}$ in relation to the most centromeric marker (CSSM066). The sex effect was estimated to be $-4.178 \pm 0.994 \mathrm{~kg}$ for the females and the additive effect was $2.122 \pm 0.735 \mathrm{~kg}$, corresponding to $7.2 \%$ of the trait mean of $29.59 \mathrm{~kg}$. The QTL allele with positive effect on birth weight was inherited from the Holstein parental breed.

\section{Discussion}

In this study we constructed a linkage map based on genotype data using a three generation pedigree in a F2 genetic design. Although markers were selected to cover the whole BTA14 at a spacing of $20 \mathrm{cM}$, the map built from the observed informative meiosis resulted in an average interval between markers of $23.36 \mathrm{cM}$. The inclusion of additional markers in these intervals would increase the probability of detecting a QTL and could also increase the significance level of the QTL for birth weight and weight at 60 days described in this paper. The position of the QTL found in this study coincides with the centromeric region of the QTL found by Morris et al. (2002), who found a BTA14 QTL between about 10 to $30 \mathrm{cM}$ which influenced growth traits such as weight at 250 and 600 days, weight gain from



Figure 2 - Chromosome F-statistic distribution for the weight at 60 days quantitative trait locus (QLT) on the chromosome 14 (BTA14). The arrows below the $\mathrm{X}$ axis indicate marker positions on the chromosome as measured from the centromere, in centimorgans (cM): CSSSM066 $(0.0 \mathrm{cM})$, ILSTS011 (16.9 cM), BMC1207 (47.8 cM), BMS740 $(67.7 \mathrm{cM})$, BMS1899 (91.6 cM), BL1036 (116.8 cM) and BMS2055 $(144.3 \mathrm{cM})$. The upper and lower horizontal lines represent threshold levels of $1 \%(\mathrm{~F}=9.61)$ and $5 \%(\mathrm{~F}=6.98)$. The QTL is located at $0.0 \mathrm{cM}$ from the centromere $(\mathrm{F}=8.34)$. The scale indicates the $95 \%$ confidence interval $(0.0 \mathrm{cM}$ to $137.5 \mathrm{cM})$. the 250 to the 400 days, gain of weight from the 400 to the 600 days and also hot carcass weight.

Other studies relating the BTA14 chromosome to growth traits have been described in the literature. Kneeland et al. (2004) identified haplotypes on BTA14 associated with three growth traits in a commercial Bos taurus line, with some of the haplotypes involving three of the markers (CSSM066, BMC1207 and BMS1899) used in the study described in the present paper. Kneeland et al. (2004) showed that haplotypes involving the BMC1207 marker at 36.2-46.2 cM and the BMS1899 marker at 52.0-67.7 cM were associated with birth weight while the haplotypes involving the CSSM066 marker at 17.0-24.0 $\mathrm{cM}$ and the BMC1207 marker at 36.2-46.2 cM were associated to postweaning average daily gain (ADG) on feed. Mizoshita et al. (2004) found five QTL related to growth traits on BTA14. ADG from 9 to 30 months during fattening, body weight at slaughter and carcass weight were located at the $45-51 \mathrm{cM}$ region, while body weight at 9 months before fattening and ADG before fattening were located at the $29-42 \mathrm{cM}$ region.

The centromeric end of BTA14 corresponds to the telomeric end of human chromosome 8 , an homology supported by a combination of cross-species chromosome painting analysis (Zoo-FISH) (Solinas-Toldo et al. 1995), comparative anchor tagged sequences (CATS) (Lyons et al. 1996) and linkage mapping using thyroglobulin restriction fragment length polymorphisms (RFLPs) (Barendse et al. 1994). Refining the map position of the identified QTL with linkage disequilibrium mapping should allow more precise boundary identification of the orthologous human chromosome segment, providing a list of positional candidate genes and expressed sequence tags (ESTs) (Coppieters et al. 1998).

With the availability of the draft sequence of the bovine genome the search for clones of the bovine genome on bacterial artificial chromosomes (BACs) containing the QTL flanking markers would be a straight forward strategy for candidate gene discovery and gene expression analysis. In the absence of a complete and annotated bovine genome sequence, detailed human-bovine comparative maps are one of the most effective tools for identification of positional candidate genes contributing to cattle QTL (Connor et al., 2006).

We found that in the F2 population (Gyr X Holstein) analyzed by us the centromeric region of the chromosome 14 influences growth traits. This not only support previously published results in the literature but also creates opportunities for other studies on candidate genes, single nucleotide polymorphism (SNP) and gene expression. Birth weight and weight at 60 days could be considered as a reproductive trait rather than a growth trait, since delivering heavier calves may affect the reproductive performance of a dam. Ashwell et al. (2004) found a daughter pregnancy rate (DPR) QTL between the CSSM066 and ILSTS011 
markers at $11 \mathrm{cM}$, while Schnabel et al. (2005) have placed a DPR QTL between the BMC1207 and BMS1899 markers with a significance level of $p<0.05$. The effects of DPR QTL may be explained by the nearby DGAT1 gene (Ashwell el al. 2004). Gonda et al. (2004) identified a QTL affecting ovulation rate on BTA14 in the USDA MARC twinning herd at $59 \mathrm{cM}$, potentially representing the same DPR QTL gene.

Exploring the QTL information on Gyr and Holstein breeding programs would require the confirmation of QTL segregation within each population as well as the effect on other traits.

\section{Acknowledgments}

The research was supported by the Brazilian agencies Embrapa - Prodetab. The Brazilian National Research Council (CNPq) provided a scholarship for M Miyata and research fellowships for LL Coutinho, LCA Regitano and ML Martinez. MF Rosário received a scholarship from the Brazilian agency FAPESP.

\section{References}

Ashwell M, Heyen D, Sonstegard T, Van Tassell C, Da Y, VanRaden P, Ron M, et al. (2004) Detection of quantitative trait loci affecting milk production, health and reproductive traits in Holstein cattle. J Dairy Sci 87:468-75.

Barendse WJ, Armitage SM, Kossarek LM, Shalom A, Kirkpatrick BW, Ryan AM, Clayton D, et al. (1994) A genetic linkage map of the bovine genome. Nat Genet 6:227-235.

Buchanan FC, Thue TD, Winkelman-Sim DC, Plante Y and Schmutz SM (2000) Two QTLs for growth map to bovine chromosome 14. Scientific Presentations $27^{\text {th }}$ International Conference on Animal Genetics. International Society for Animal Genetics, Minneapolis, pp 22-26.

Casas E, Shackelford SD, Keele JW, Stone RT, Kappes SM and Koohmaraie M (2000) Quantitative trait loci affecting growth and carcass composition o cattle segregating alternative forms of myostatin. J Anim Sci 78:560-569.

Casas E, Stone RT, Keele JW, Shackelford SD, Kappes SM and Koohmaraie M (2001) A comprehensive search for QTL affecting growth and carcass composition of cattle segregating alternative form of myostatin gene. J Anim Sci 79:854-860.

Casas E, Shackelford SD, Keele JW, Koohmaraie M, Smith TPL and Stone RT (2003) Detection of quantitative trait loci for growth and carcass composition in cattle. J Anim Sci 81:2976-83.

Churchill GA and Doerge RW (1994) Empirical threshold values for quantitative trait loci mapping. Genetics 138:963-971.

Connor EE, Ashwell MS, Schnabel R and Williams JL (2006) Comparative mapping of bovine chromosome 27 with human chromosome 8 near a dairy form QTL in cattle. Cytogenet Genome Res 112:98-102.

Coppieters W, Riquet J, Arranz J, Berzi P, Cambisano N, Grisart B, Karim L, et al. (1998) A QTL with major effect on milk yield and composition maps to bovine chromosome 14 . Mamm Genome 9:540-544.

Davis GP, Hetzel DJS, Corbet NJ, Scacheri S, Lowden S, Renaud J, Mayne C, et al. (1998) The mapping of QTL for birth weight in a tropical beef herd. Proceedings $6^{\text {th }}$ World Congress on Genetics Applied to Livestock Production. Armidale, Australia, papers 26:441-444.

Gasparin G, Miyata M, Coutinho LL, Martinez ML, Silva MVGB, Machado MA, Campos AL and Regitano LCA (2005) Quantitative trait loci affecting birth weight on bovine chromosome 5 in a F2 Gyr x Holstein population. Genet Mol Biol 28:670-676.

Gonda MG, Arias JA, Shook GE and Kirkpatrick BW (2004) Identification of an ovulation rate QTL in cattle on BTA14 using selective DNA pooling and interval mapping. Anim Genet 35:298-304.

Green P, Falls K and Croocks S (1990) CRI-MAP version 2.4. St. Louis, University School of Medicine.

Hallerman EM, Nave A, Soller M and Beckmann JS (1988) Screening of Israeli Holstein-Friesian cattle for restriction fragment length polymorphisms using homologous and heterologous deoxyribonucleic acid probes. J Dairy Sci 71:3378-3389.

Haley CS, Knott SA and Elsen JM (1994) Mapping quantitative trait loci in crosses between outbred lines using least squares. Genetics 136:1195-1207.

Hetzel J, Davis G, Corbet N, Scacheri S, Mayne C, Scott J and Stevenson R (1997) Localisation of quantitative trait loci (QTL) for growth traits in Bos Taurus x Bos indicus cattle. Abstracts V Conference Plant \& Animal Genome, San Diego, pp 12-18.

Kim JJ, Farnir F, Savell J and Taylor JF (2003) Detection of quantitative trait loci for growth and beef carcass fatness traits in a cross between Bos taurus (Angus) and Bos indicus (Brahman) cattle. J Anim Sci 81:1933-1942.

Kneeland J, Li C, Basarab J, Snelling WM, Benkel B, Murdoch B, Hansen C and Moore SS (2004) Identification and fine mapping of quantitative trait loci for growth traits on bovine chromosomes 2, 6, 14, 19, 21 and 23 within one commercial line of Bos Taurus. J Anim Sci 82:3405-3414.

Koots KR, Gibson JP, Smithan C and Wilton JW (1994a) Analyses of published genetic parameter estimates for beef production traits. 1 Heritability. Anim Breed Abstr 62:309-337.

Koots KR, Gibson JP and Wilton JW (1994b) Analyses of published genetic parameter estimates for beef production traits. 2 Phenotypic and genetic correlations Anim Breed Abstr 62:825-853.

Lynch M and Walsch B (1998) Genetics and Analysis of Quantitative Traits. Sinauer Associates Inc., Massachussetts, 980 pp.

Lyons AL, Laughlin TF, Copeland NG, Jenkins NA, Womack JE and O'Brien SJ (1996) Comparative anchor tagged sequences for integrative mapping of mammalian genomes. Nat Genet 15:47-56.

Machado MBB, Alencar MM, Pereira AP, Oliveira HN, Casas E, Coutinho LL and Regitano LCA (2003) QTL affecting body weight in a candidate region of cattle chromosome 5 . Genet Mol Biol 26:259-265.

MacNeil MD and Grosz MD (2002) Genome-wide for QTL affecting carcass traits in Hereford $\mathrm{x}$ composite double backcross populations. J Anim Sci 80:2316-2324.

Marshall TC, Slate J, Kruuk LEB and Pemberton JM (1998) Statistical confidence for likelihood-based paternity inference in natural populations. Mol Ecol 7:639-655. 
Mizoshita K, Watanabe T, Hayashi H, Kubota C, Yamakuchi H, Todoroki J and Sugimoto Y (2004) Quantitative trait loci analysis for growth and carcass traits in a half-sib family on purebred Japanese Black (Wagyu) cattle. J Anim Sci 82:3415-3420.

Morris CA, Pitchford WS, Cullen NG, Hickey SM, Hyndman DL, Crawford AM and Bottema CDK (2002) Addictive effects of two growth QTL on cattle chromosome 14. Proceedings $7^{\text {th }}$ World Congress of Genetics Applied to Livestock Production. Montpellier, France, pp 7:19-23.

Ott J (1999) Analysis of Human Genetic Linkage. 3rd edi. Ed Johns Hopkins University Press, Baltimore, 382 pp.

Schnabel RD, Sonstegard TS, Taylor JF and Ashwell MS (2005) Whole genome scan to detect qtl for milk production, con- formation and functional traits in two U.S. Holstein families. Anim Genet 36:408-416.

Seaton G, Haley CS, Knott SA, Kearsey M and Visscher PM (2002) QTL Express: Mapping quantitative trait loci in simple and complex pedigrees. Bioinformatics 18:339-340.

Solinas-Toldo S, Lengauer C and Fries R (1995) Comparative genome map of human and cattle. Genomics 27:489-496.

Stone RT (1999) A primary screen of the bovine genome for quantitative trait loci affecting carcass and growth traits. J Anim Sci 77:1379-1384.

Visscher PM, Thompson R and Haley CS (1996) Confidence intervals in QTL mapping by bootstrapping. Genetics 143:1013-1020.

Associate Editor: Pedro Franklin Barbosa 